\title{
Prevalence, quality of life assessment of urinary incontinence using a validated tool (ICIQ-UI SF) and bothersomeness of symptoms among rural community: dwelling women in Southwest, Nigeria
}

\author{
Olajide O. Abiola ${ }^{1 *}$, Ajibola Idowu ${ }^{2}$, Olumuyiwa A. Ogunlaja ${ }^{3}$, Oyeronke T. Williams-Abiola ${ }^{4}$, \\ Sola C. Ayeni ${ }^{1}$
}

\begin{abstract}
${ }^{1}$ Department of Surgery, Bowen University Teaching Hospital, Ogbomoso, Oyo state, Nigeria
${ }^{2}$ Department of Community Medicine, Bowen University Teaching Hospital, Ogbomoso, Oyo state, Nigeria

${ }^{3}$ Department of Obstetrics \& Gyneacology, Bowen University Teaching Hospital, Ogbomoso, Oyo state, Nigeria

${ }^{4}$ Department of Medicine, Obafemi Awolowo University Teaching Hospital, Ile-Ife, Osun state, Nigeria
\end{abstract}

Received: 20 March 2016

Accepted: 04 April 2016

\section{*Correspondence:}

Dr. Olajide O. Abiola,

E-mail: ooabiola2015@gmail.com

Copyright: (C) the author(s), publisher and licensee Medip Academy. This is an open-access article distributed under the terms of the Creative Commons Attribution Non-Commercial License, which permits unrestricted non-commercial use, distribution, and reproduction in any medium, provided the original work is properly cited.

\section{ABSTRACT}

Background: Urinary incontinence (UI) is a debilitating disease which impacts on quality of life (QoL) of affected individuals. Estimates of the burden of the diseases varied widely due to different definitions of the disease by different researchers. With the use of a validated screening tool-International Consultation on Incontinence Questionnaire- Urinary Incontinence Short Form (ICIQ-UI SF) we sought to determine the prevalence of UI among women in a rural Nigerian community; examined their self-reported QoL and perceived bothersomeness of the symptoms.

Methods: A cross-sectional descriptive epidemiological study among rural community-dwelling women in South west, Nigeria with 229 participants selected by multi-stage sampling technique. The study was conducted using ICIQUI SF questionnaire with additional data on socio-demographics and bothersomeness of the symptoms. Correlates of QoL were determined with Spearman's rho correlation and associated factors of bothersomeness determined by chi square and logistic regression.

Results: Prevalence was $12.6 \%$ and stress UI was the commonest type. Poor QoL reported in 65.5\% of those afflicted with UI. Worsening QoL had a positive correlates with Age $(\mathrm{p}<0.010)$, amount of urine loss $(\mathrm{p}<0.001)$, frequency of urine leakage $(\mathrm{p}<0.001)$ and ICIQ scores $(\mathrm{p}<0.001)$. Perceived bothersomeness of symptoms were associated with ICIQ score of $\geq 8$ ( $\mathrm{p}<0.001$; OR: $1.810 ; 95 \%$ CI: $1.220-2.684)$.

Conclusions: Prevalence was $12.6 \%$ with poor QoL in substantial proportion of the respondents with UI worsened by advancing age, increase in quantity of urine loss, increase in frequency of urine leakage and ICIQ score. Perceived bothersomeness of symptoms was associated with ICIQ score of $\geq 8$.

Keywords: Prevalence, Quality of life, Bothersomeness, Urinary incontinence, Nigeria

\section{INTRODUCTION}

Urinary incontinence (UI) is described by international continence society (ICS) as involuntary urine loss, objectively demonstrable and is a social or hygienic problem. $^{1}$ It is reported to occur world-wide with significant variation in its prevalence which ranges from $4.8 \%$ to $58.4 \%$. $^{2}$ The wide variation in the prevalence rate has been attributed to differences in definition of the term 'incontinence' by different researchers. ${ }^{3}$ This underscores the need for a standardized screening tool for epidemiological study. In 1998, World Health 
Organization

Consultation

development

International

sponsored

International on Incontinence (ICI) initiated the of a validated questionnaire called Consultation on Incontinence Questionnaire- Urinary Incontinence Short Form (ICIQUI SF).This was a validated, brief and simple questionnaire which allows for assessment of the prevalence, frequency, perceived cause of urinary incontinence and its impact on everyday life. It has been found useful in outcome and epidemiological research as well as in routine clinical practice. ${ }^{4}$

In an earlier epidemiological study of UI in Ibadan- a predominantly urban setting in Southwest, Nigeria (Ibadan urinary incontinence household survey) the prevalence rate of UI among women was 7.2\%.5 The prevalence was low compared to $30.9 \%$ and $40 \%$ reported in community-based surveys among Chinese and British women respectively. ${ }^{6,7}$ The relatively low prevalence rate in the study was attributed to the culture of silence of divulging medical disorders to stranger by the women and the skewness of the study towards younger age group. ${ }^{5}$

Urinary incontinence is a debilitating condition with impact on physical and psychosocial aspect of life of an affected individual with consequent effect on the quality of life (QoL) of the sufferers. Some of the reported effects of urinary incontinence which had impact on the QoL of affected individuals include skin irritation, cellulitis, poor self-esteem, social withdrawal, depression and sexual dysfunction. ${ }^{8}$

Despite the negative impact on quality of life, health seeking behaviour of women have been reported to be low world-wide with only $13-55 \%$ of women with symptoms sought medical care. ${ }^{9}$ Many women have adapted various lifestyles modifications such as reducing fluid intake and keeping the bladder empty, limiting social interaction, hygiene measures, avoiding sexual activities as a means of coping with this condition with the symptoms becoming less bothersome to them. ${ }^{8,10}$ However, patients who cope less with the symptoms may have some degree of bothersomeness about their condition. $^{11}$

In most rural communities in Nigeria, there are limited health care resources to managed patients with such debilitating conditions which required specialized care. ${ }^{12}$ It is pertinent to identify patients that cope less well with their conditions for prompt intervention in the face of limited health care resources.

This study sought to determine prevalence of UI among women in a rural Nigerian community; their self-reported QoL using a validated tool (ICIQ-UI SF); and the bothersomeness of the symptoms as perceived by the respondents.

\section{METHODS}

The study was conducted in a selected rural community (Lagbedu-with a population of 5,012) in Ogbomoso South Local Government Area (LGA) of Oyo State, Nigeria which has a population of 100,379 (National census). The LGA has 10 wards most of which are predominantly rural. The inhabitants of the LGA are mostly farmers though a sizeable number of the people are civil servants while others engaged in various degrees of trading activities. Most of the people are of Yoruba extract but other tribes such as Hausa and Igbo are equally residing in the LGA. All the three prominent Nigerian religions (Christianity, Islam and Traditional religion) are been practiced by the people in the community.

\section{Study design}

The study employed cross-sectional descriptive epidemiological study design.

\section{Sample size determination}

The sample size for this study was determined by the formula $n=t^{2} \times p(1-p) / m^{2}$ with $n$ : required sample size; $t$ : confidence level at $95 \%$ (standard value of 1.96); $\mathrm{p}$ : estimated prevalence of urinary incontinence in the projected area; m: margin of error at $5 \%$ (standard value of 0.05 ).

Using the prevalence rate of $7.2 \%$ from Ibadan urinary incontinence household survey (IUIHS) done in South west Nigeria and correction for difference in the cluster design with a design defect (D) of 2, the Initial sample size was $206 .^{3}$

A response rate of $90 \%$ was envisaged during the study design based on the response rate in an earlier pilot study in a community different from the one used for the main study. Thus, the final sample size was determined with the formula: $\mathrm{nf}=\mathrm{N} /$ percentage response rate where $\mathrm{nf}=$ final sample size, $\mathrm{N}=$ initial sample size. Hence, the final sample size was $(\mathrm{nf}=206 / 0.9) 229$.

\section{Sampling method}

Respondents were selected using multi-stage sampling technique; the first stage involved stratification of the wards in the local government area (LGA) into predominantly rural and urban wards based on 2006 National population result for the LGA. In stage 2, a predominantly rural ward was selected by balloting from the predominantly rural wards while the third stage involved selection of one community from the selected rural ward using simple random method. Next stage involved division of the selected community (Lagbedu) into clusters, using the available streets. A listing of such clusters was made and one of them selected by balloting. 
All the households in the selected cluster were involved in the study.

\section{Inclusion criterion}

Women above the age of 18 years who were permanent residents in the selected cluster and adjudged capable of answering our research questions correctly and who gave consents to participate were involved in the study.

\section{Exclusion criterion}

Women who are either too sick to volunteer information or refused to give their consents were exempted from the study.

\section{Ethical consideration}

Ethical approval to embark on this study was sought from the Ethical Review Committee of Bowen University Teaching Hospital, Ogbomoso. Consents were obtained from study participants and those who failed to give their consents were excluded from the study. Participation was entirely voluntary and respondents who were found to be incontinent of urine were counseled and appropriately referred to Urology clinic of Bowen University Teaching Hospital for expert care. Absolute confidentiality was employed regarding the data collected; questionnaires were made anonymous using questionnaire identity numbers instead of respondents' names. Moreover, only computers with passwords were used for data storage and only the key members of the research team had access to the data.

\section{Data collection method and instrument}

Quantitative data were collected by five trained research assistants over a period of a month using an interviewer administered questionnaire. The questionnaire is made up of three sections (Appendix I).

Section 1: Consist of set of questions to collect data on socio-demographic characteristics of the respondents (Age, Level of Education and Occupation).

Section 2: This was made up of International consultation on Incontinence Questionnaire- Urinary Incontinence Short Form (ICIQ-UI SF) - a validated and brief questionnaire made up of four questions (Appendix I). The first question was related to screening for UI and its frequency of urinary leakage; the second question assessed the volume of urine leakage; the third question was related to patient's self-reported impact of UI on quality of life as it affected their daily activities while the forth question assessed symptoms associated with different type of UI to determine the type of UI (stress, urge, mixed and total urinary incontinence). The sum of the scores from the first three questions gave the ICIQ score (0-21) which was used to determine the severity of UI.
Section 3: This section contained a question: "Does your urine leakage bother you on your physical activities, social interraction and psychological wellbeing?" This was used for assessment of bothersomeness of UI symptoms in the respondents. Response was based on a 2-point scale: Bothered and Not Bothered.

\section{Operational definitions}

\section{Urinary Incontinence}

Any respondent who leaked urine at least once a week or more than was categorized as having urinary incontinence.

Frequency of incontinence was categorized as:

Mild: If the respondent leaked urine about once a week.

Moderate: If 2 or 3 times a week or about once a day.

Severe: If urine leaked several times a day/ all the time.

\section{Severity of Urinary incontinence was classified using ICIQ Scores as:}

Mild: ICIQ score of 0-7

Moderate: ICIQ score of 8-14

Severe: ICIQ score of $15-21$

\section{Stress incontinence}

Was defined as urine leakage associated with physical activities, exercise, straining, coughing, sneezing, laughing or crying.

Urge incontinence was defined as urine leakage which occur with sudden, strong desire to void or leakage before getting to the toilet.

Mixed incontinence was referred to features associated with both stress and urge urinary incontinence.

Total incontinence was defined as continuous leakage of urine.

\section{Quality of life (QoL) assessment}

This was assessed by impact of UI symptoms on everyday life. For this study, the third question of ICIQUI SF questionnaire (appendix I): "Overall, how much does leaking urine interfere with your everyday life?" was used for its assessment. Response was graded from 0 (Not at all) to 10 (a great deal). For the purpose of the study, a grade of average and below (0-5) was regarded as good QoL while a grade above average (6-10) - poor QoL. 


\section{Data analysis}

Data analysis was done using Statistical Package for Social Sciences (version 21). The preliminary descriptive analysis was done using appropriate method of data summarizations and presentations (Tables). Spearman rho correlation with significance at $0.05(p<0.05)$ was used to assess the relationship of quality of life with sociodemographic characteristics, frequency of urinary leakage, amount of urine leakage, severity of UI(ICIQ scores) and type of UI. Bivariate analysis with Pearson's chi square with level of significance at $0.05(\mathrm{p}<0.05)$ was used to assess the relationship of socio-demographic characteristics, ICIQ scores and type of UI with bothersomeness of urinary incontinence symptoms and further analysis of variables associated with bothered UI symptoms by logistic regression at $95 \%$ confident interval.

\section{Limitation of the study}

Since the study relied on participants remembering past events and divulging information on their medical conditions, it may not be totally free from recall bias and denial of the condition. Moreover, urinary incontinence is a stigmatizing disease; therefore, the prevalence reported in this study may not be a true reflection of the true burden of urinary incontinence in the community.

\section{RESULTS}

Table 1: Socio-demographic characteristics of respondents.

\begin{tabular}{|lll|}
\hline Variable & $\begin{array}{l}\text { Frequency } \\
(\mathbf{n = 2 2 9})\end{array}$ & Percentage \\
\hline Age groups & & \\
\hline $21-30$ & 3 & 1.3 \\
\hline $31-40$ & 59 & 25.8 \\
\hline $41-50$ & 57 & 24.9 \\
\hline $51-60$ & 68 & 29.7 \\
\hline$\geq 61$ & 42 & 18.3 \\
\hline Level of education & & \\
\hline No formal education & 59 & 25.8 \\
\hline Primary & 112 & 48.9 \\
\hline Secondary & 46 & 20.1 \\
\hline Tertiary & 12 & 5.2 \\
\hline Occupation & & \\
\hline Civil Servants & 16 & 7.0 \\
\hline Farming & 140 & 61.2 \\
\hline None & 28 & 12.2 \\
\hline Student & 1 & 0.4 \\
\hline Trading & 44 & 19.2 \\
\hline
\end{tabular}

Two hundred and twenty nine respondents gave their consent to be interviewed. The age range of the respondents was 24 to 74 years with a mean of $50 \pm 7.23$ years. The age distribution, level of education and occupation of respondents are as shown in Table 1.

Twenty nine respondents reported experience of involuntary leakage of urine (urinary incontinence) giving a prevalence rate of $12.7 \%$. The sociodemographic characteristics of respondents with urinary incontinence are as depicted in Table 2.

Table 2: Socio-demographic characteristics of respondents with urinary incontinence.

\begin{tabular}{|lll|}
\hline Variable & $\begin{array}{l}\text { Frequency } \\
(\mathbf{n = 2 9})\end{array}$ & Percentages \\
\hline Age groups & & \\
\hline $21-30$ & 3 & 10.3 \\
\hline $31-40$ & 7 & 24.1 \\
\hline $41-50$ & 9 & 31.1 \\
\hline $51-60$ & 6 & 20.7 \\
\hline$\geq 61$ & 4 & 13.8 \\
\hline Level of education & & \\
\hline $\begin{array}{l}\text { No formal } \\
\text { education }\end{array}$ & 6 & 20.7 \\
\hline Primary & 8 & 27.6 \\
\hline Secondary & 15 & 51.7 \\
\hline Occupation & & \\
\hline Farming & 15 & 51.7 \\
\hline Trading & 11 & 37.8 \\
\hline Student & 1 & 3.5 \\
\hline Unemployed & 2 & 7.0 \\
\hline
\end{tabular}

Thirteen of the respondents with UI (44.8\%) described the frequency of their urinary leakage about once a week (mild in frequency), 12 of the respondents (41.4\%) described it as moderate (leakage of urine 2or3 times a week or about once a day) while 4 respondents (13.8\%) described it as severe in frequency (leaked several times a day/ all the time).

Twenty two of the respondents (75.9\%) with urinary incontinence described the amount of urine leakage as small while 7 respondents $(24.1 \%)$ described it as moderate.

Seventeen $(58.6 \%)$ of the 29 respondents with UI had ICIQ scores within 0-7 (Mild UI), 6 of the respondents (20.7\%) had ICIQ scores of $8-14$ (Moderate UI) while the remaining 6 respondents $(20.7 \%)$ had ICIQ scores of 15-21 (Severe UI).

Ten respondents with UI $(34.5 \%)$ reported good QoL with the grades from 3 to 5 while 19 respondents with UI $(65.5 \%)$ reported poor QoL with the grades from 6 to 9.

Seventeen of the respondents $(58.6 \%)$ with UI had stress urinary incontinence, 8 respondents $(27.6 \%)$ had urge urinary incontinence and 4 respondents $(13.8 \%)$ had mixed urinary incontinence. 
Correlations of QoL with age, level of education, occupation, frequency of urinary leakage, amount of urine leakage, ICIQ score (severity of UI) and type of UI using spearman rho correlation were shown in Table 3. All the variables had a statistically significant positive correlation with the QoL except the type of UI. The amount of urine loss had the strongest correlation while Age had the least correlation.

Table 3: Spearman rho correlation of quality of life with age, frequency of urinary leakage, amount of urine loss, ICIQ Scores and type of UI.

\begin{tabular}{|c|c|c|c|c|c|}
\hline $\begin{array}{l}\text { Quality of } \\
\text { life score }\end{array}$ & Age & $\begin{array}{l}\text { Freque- } \\
\text { ncy of } \\
\text { leakage }\end{array}$ & $\begin{array}{l}\text { Amount } \\
\text { of urine } \\
\text { loss }\end{array}$ & $\begin{array}{l}\text { ICIQ } \\
\text { scores }\end{array}$ & $\begin{array}{l}\text { Type } \\
\text { of UI }\end{array}$ \\
\hline $\begin{array}{l}\text { Correlation } \\
\text { coefficient }\end{array}$ & $0.471^{*}$ & $0.575^{*}$ & $1.000^{*}$ & $0.947^{*}$ & 0.187 \\
\hline $\begin{array}{l}\text { Sig. (2- } \\
\text { tailed) }\end{array}$ & 0.010 & 0.001 & 0.001 & 0.001 & 0.331 \\
\hline $\mathrm{N}$ & 29 & 29 & 29 & 29 & 29 \\
\hline
\end{tabular}

Eight respondents $(27.6 \%)$ were bothered by their UI symptoms while 21 respondents with UI $(72.4 \%)$ reported not to be bothered by their symptoms.

Bi-variate analysis of Age, Level of Education, Occupation, ICIQ score (severity of UI) and Type of UI with bothersomeness of urinary incontinence using Chisquare test was represented in Table 4. Only ICIQ score had a statistically significant association with bothersomeness of UI symptoms with an odd ratio (OR) of 1.810 (95\% CI, 1.220- 2.684, $\mathrm{p}<0.003)$.
Table 4: Bi-variate analysis Socio-demographics and ICIQ scores with bothersomeness of urinary incontinence.

\begin{tabular}{|c|c|c|c|c|}
\hline \multicolumn{5}{|c|}{ Bothersomeness of UI } \\
\hline Factors & $\begin{array}{l}\text { Non- } \\
\text { bothered } \\
\text { UI }(\%) \\
(n=21)\end{array}$ & $\begin{array}{l}\text { Bothered } \\
\text { UI }(\%) \\
(n=8)\end{array}$ & $\chi^{2}$ & $\mathrm{p}$ \\
\hline \multicolumn{5}{|l|}{ Age groups } \\
\hline $21-30$ & $2(9.5)$ & $1(12.5)$ & & \\
\hline $31-40$ & $7(33.3)$ & $0(0.0)$ & & \\
\hline $41-50$ & $7(33.3)$ & $2(25.0)$ & & \\
\hline $51-60$ & $3(14.3)$ & $3(37.5)$ & & \\
\hline$\geq 61$ & $2(9.5)$ & $2(25.0)$ & 5.361 & 0.252 \\
\hline \multicolumn{5}{|c|}{ Level of education } \\
\hline $\begin{array}{l}\text { No formal } \\
\text { education }\end{array}$ & $3(14.3)$ & $3(37.5)$ & & \\
\hline Primary & $6(28.6)$ & $2(25.0)$ & & \\
\hline Secondary & $12(57.1)$ & $3(37.5)$ & 1.968 & 0.374 \\
\hline \multicolumn{5}{|l|}{ Occupation } \\
\hline Trading & $9(42.9)$ & $2(25.0)$ & & \\
\hline Farming & $9(42.9)$ & $6(75.0)$ & & \\
\hline Student & $1(4.8)$ & $0(0.0)$ & & \\
\hline Unemployed & $2(9.5)$ & $0(0.0)$ & 2.787 & 0.426 \\
\hline \multicolumn{5}{|l|}{ ICIQ scores } \\
\hline Mild & $17(81.0)$ & $0(0.0)$ & & \\
\hline Moderate & $3(14.3)$ & $3(37.5)$ & & \\
\hline Severe & $1(4.8)$ & $5(62.5)$ & 17.319 & $<0.001$ \\
\hline \multicolumn{5}{|l|}{ Types of UI } \\
\hline Stress & $12(57.1)$ & $5(62.5)$ & & \\
\hline Urge & $5(23.8)$ & $3(37.5)$ & & \\
\hline Mixed & $4(19.0)$ & $0(0.0)$ & 1.946 & 0.378 \\
\hline
\end{tabular}

†ICIQ scores- International Consultation on Incontinence Questionnaire scores ; UI- Urinary Incontinence

Table 5: Simple linear regression of bothersomeness of symptoms and ICIQ scores.

\begin{tabular}{|lllllllll|}
\hline Variable & & & & & & \multicolumn{3}{c|}{ 95.0\% C.I. } \\
\hline ICIQ & B & S.E. & Wald & df & Sig. & Exp (B) & Lower & Upper \\
\hline Constant & 0.593 & 0.201 & 8.705 & 1 & 0.003 & 1.810 & 1.220 & 2.684 \\
\hline
\end{tabular}

\section{DISCUSSION}

The prevalence of Urinary incontinence (UI) among women in the rural community in Nigeria was low $(12.6 \%)$ when compared to prevalence rate in community based studies in developed countries reported to be $30.9 \%$ and $40 \%$ among Chinese and British women respectively but it was similar to a reported prevalence rate of $11.5 \%$ among rural dwelling women in Pakistan- a developing nation like Nigeria. ${ }^{6,7,13}$ However, this finding in rural community in South west, Nigeria was found to be higher than an earlier reported prevalence of $7.2 \%$ of women that ever leaked urine and $2.8 \%$ currently leaking at the time of study among women in Ibadan ( a majorly urban city) in Southwest, Nigeria. ${ }^{5}$ This difference in prevalence rate may be due to the skewness of the earlier study towards younger age group (mean age of $33.2 \pm 14.7$ years) whereas in this study, the average age was $50 \pm 7.23$ years. Also, the difference in prevalence rate may be due to the different screening tools deployed in the epidemiological studies. In this study, a validated tool of ICIQ-UI SF questionnaire was used. Therefore, to ascertain possible difference of prevalence rate of UI among urban dwelling and rural dwelling women in 
Nigeria, further studies will be required using the same validated screening tool among urban dwelling women.

Most prevalent type of UI was stress UI (58.6\%), followed by urge UI $(27.6 \%)$ and mixed UI (13.8\%).This finding further corroborated earlier reports from epidemiological studies of UI in Nigeria in which stress incontinence was the commonest type of UI among women with UI. ${ }^{5,14}$

A considerable number of the respondents $(65.5 \%)$ reported poor QoL, a finding similar to previous reports of negative impact of UI on QoL of affected women. ${ }^{15,16}$ In this study, the significant correlates of the QoL of the respondents with UI were Age, Amount of urine loss, frequency of urinary leakages and severity of UI (ICIQ Scores). All of these variables had statistically significant positive correlates which implies QoL may worsen with an advancing age, increase in quantity of urine loss, increase in frequency of urine leakage and severity of UI. However, the type of UI correlation with QoL was statistically insignificant.

Only a few number of respondents with UI (27.6\%) were bothered by their symptoms despite considerable number of them reported poor QoL (65.5\%). There is a possibility that some of the respondents may have adapted various lifestyles modifications in coping with their symptoms which overtime may become less bothersome to them as it was reported in a study among Turkish women by Beji et al. ${ }^{17}$ However, this assumption could not be ascertained from this study.

Furthermore, ICIQ scores had associations with the perception of bothersomeness of the symptoms by the respondents. Respondents with UI who were bothered by their symptoms had ICIQ score of at least 8 and above $(\mathrm{p}<0.001)$. The ICIQ score (severity of UI) which was determined by frequency of urine leakage, amount of urine leakage and impact of UI symptoms on the QOL, had approximately twice the chance of predicting the bothersomeness of UI symptoms in respondents afflicted by the condition (95\% CI, 1.220- 2.684; p<0.003). This was consistent with earlier studies which reported severity of UI as an important factor associated with bothered UI. ${ }^{11,18}$

\section{CONCLUSION}

Prevalence rate was $12.6 \%$ with poor QoL in substantial proportion of the respondents with UI worsened by advancing age, increase in quantity of urine loss, increase in frequency of urine leakage and ICIQ score (severity of UI). However, only a sizeable number of respondents with UI were bothered by their condition. The perceived bothersomeness of symptoms was associated with ICIQ score of $\geq 8$. Thus, ICIQ-UI SF questionnaires as a screening tool for UI in a community can assist in identifying those afflicted by UI who are likely to be bothered by their symptoms and may likely to seek medical attention. This may be of value in allocating scarce health care resources to those who are most in need of it.

\section{Funding: No funding sources \\ Conflict of interest: None declared}

Ethical approval: The study was approved by Bowen

University Teaching Hospital Ethical Review Committee

\section{REFERENCES}

1. Horrocks S, Somerset M, Stoddart H, Peters TJ. What prevents older people from seeking treatment for urinary incontinence? A qualitative exploration of barriers to the use of community continence services. Family Practice. 2004;21(6):691-8.

2. Minassian VA, Drutz HP, Al-Badr A. Urinary incontinence as a worldwide problem. Int $\mathbf{J}$ Gynaecol Obstet. 2003;82(3):327-38.

3. Thom D. Variation in estimates of urinary incontinence prevalence in the community: effects of differences in definition, population characteristics and study type. J Am Geriatr Soc. 1998;46(4):473-80.

4. Avery K, Donovan J, Peters TJ, Shaw C, Gotoh M, Abrams P. ICIQ: A Brief and Robust Measure for Evaluating the Symptoms and Impact of Urinary Incontinence. Neurourology and Urodynamics. 2004;23:322-30.

5. Ojengbede OA, Morhason-Bello IO, Adeodokun BO, Okonkwo NS, Kolade CO. Prevalence and the associated trigger factors of urinary incontinence among 5000 black women in sub-Saharan Africa: Findings from a community survey. BJUI. 2011;107:1793-800.

6. Zhu L, Lang J, Liu C, Han S, Huang J, Li X. The epidemiological study of women with urinary incontinence and risk factors for stress incontinence in China. Menopause. 2009;16(4):831-6.

7. Cooper J, Annappa M, Quigley A, Dracocardos D, Bondili A, Mallen C. Prevalence of female urinary incontinence and its impact on quality of life in a luster population in the United Kingdom. Primary health care research and development. 2014;2:1-6.

8. Shumaker SA, Wyman JF, Uebersax JS, Mc Clish D, Fantl JA. Health- related quality of life measures for women with urinary incontinence: The incontinence impact questionnaire and urogenital distress inventory. Continence program in women research group. Qual of life Res. 1994;3(5):291-306.

9. Perera J, Kirthinanda DS, wijeratne S, Wickramarachchi TK. Descriptive cross-sectional study on prevalence, perceptions, predisposing factors and health seeking behaviour of women with stress urinary incontinence. BMC Women's Health. 2014;14:78.

10. St. John W, Griffiths S, Wallis M, McKenzie S. Women's management of urinary incontinence in daily living. J Wound Ostomy Continence Nurs. 2013;40(5):524-32. 
11. Wan XJ, Li JJ, Wang XJ, Zhang Y, Liu Y, Wu C. The bothersomeness of female urinary incontinence and its influencing factors: Study from Chinese city. Intern J Nurs Sci. 2014;1(1):58-63.

12. Oladipo JA. Utilization of health care services in rural and urban areas: a determinant factor in planning and managing health care delivery systems. African Health Sciences. 2014;14(2):32233.

13. Jokhio AH, Rizvi RM, Rizvi J, Macarthur C. Urinary incontinence in women in rural Pakistan: prevalence, severity, associated factors and impact on life. BJOG. 2013;120(2):180-6.

14. Adaji SE, Shittu OS, Bature SB, Nasir S, Olatunji O. Suffering in silence: pregnant women's experience of urinary incontinence in Zaria, Nigeria. Eur J Obstet Gynecol Reprod Biol. 2010;150(1):1923.

15. Ko Y, Lin SJ, Salmon JW, Bron MS. The impact of urinary incontinence on quality of life of the elderly. Am J Manag Care. 2005;11:S103-11.
16. Teunissen D, van den Bosch W, van Weel C, LagroJanssen T. It can always happen: the impact of urinary incontinence on elderly men and women. Scand J Prim Health Care. 2006;24:166-73.

17. Beji NK, Ozbas A, Aslan E, Bilgic D, Erkan HA. Overview of the social impact of urinary incontinence with a focus on Turkish women. Urol Nurs. 2010;30(6):327-34.

18. Centinel B, Demirkesen O, Tarcan T, Yalcin O, Kocak T, Senocak M. Hidden female urinary incontinence in urology and obstetrics and gyneacology outpatient clinics in Turkey. What are the determinants of bothersome urinary incontinence and help-seeking behaviour? Int Urogynecol J. 2007;18(6):659-64.

Cite this article as: Abiola OO, Idowu A, Ogunlaja OA, Williams-Abiola OT, Ayeni SC. Prevalence, quality of life assessment of urinary incontinence using a validated tool (ICIQ-UI SF) and bothersomeness of symptoms among rural community: dwelling women in Southwest, Nigeria. Int J Community Med Public Health 2016;3:989-97. 


\section{Appendix I: Questionnaire}

\section{Section 1: Socio-demographic characteristics}

Age (in years)

Level of Education: No formal education ( ); Primary ( ); Secondary ( ); Tertiary ( )

\section{Occupation}

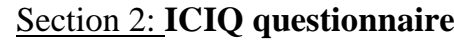

ICIQ-UI Short Form
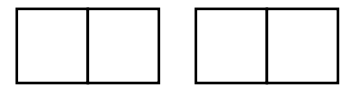

Initial Number
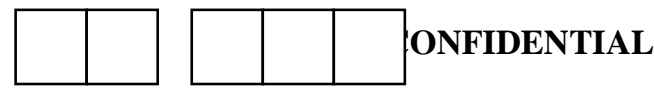

ONFIDENTIAL

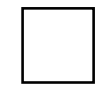

DAY

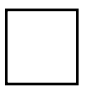

MONTH
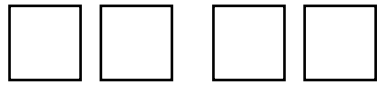

YEAR

Many people leak urine some of the time. We are trying to find out how many people leak urine, and how much this bothers them. We would be grateful if you could answer the following questions, thinking about how you have been, on average, over the PAST FOUR WEEKS

1 Please write in your date of birth:

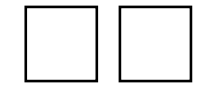

DAY

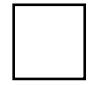

MONTH
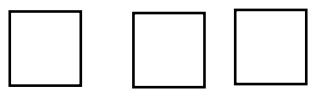

YEAR

2 Are you (tick one):

FEMALE MALE
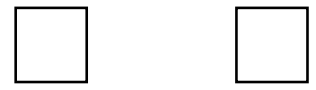

3 How often do you leak urine? (Tick one box)

Never 0

About once a week or less often 1

Two or three times a week 2

About once a day 3

Several times a day 4

All the time 5

4 We would like to know how much urine you think leaks.

How much urine do you usually leak (whether you wear protection or not)?

(Tick one box)

None 0

A small amount 2

A moderate amount 4

A large amount 6

5 Overall, how much does leaking urine interfere with your everyday life?

Please ring a number between 0 (not at all) and 10 (a great deal)

012345678910

Not at all a great deal

ICIQ score: sum scores $3+4+5$

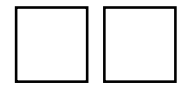


6 When does urine leak? (Please tick all that apply to you)

Never - urine does not leak

Leaks before you can get to the toilet

Leaks when you cough or sneeze

Leaks when you are asleep

Leaks when you are physically active/ exercising

Leaks when you have finished urinating and are dressed

Leaks for no obvious reason

Leaks all the time

Thank you very much for answering these questions.

Copyright @ "ICIQ Group"

\section{Section 3: Bothersomeness of symptoms}

Does your urine leakage bother you on your physical activities, social interraction and psychological wellbeing? (Tick as appropriate)

I am bothered ( ); I am not bothered ( ) 